\title{
Educational Immersive Simulation Game Design to Enhance Understanding of Corn-Water-Ethanol-Beef System Nexus
}

\author{
Dr. Deepak R. Keshwani, University of Nebraska, Lincoln
}

Dr. Deepak Keshwani is an associate professor of Biological Systems Engineering at the University of Nebraska-Lincoln. In addition to research in the area of bioprocess modeling, Dr. Keshwani is engaged in teaching and advising students across two academic colleges and is involved in numerous campus-wide student success initiatives.

\section{Mr. Ryan Drew Anderson, University of Nebraska, Lincoln}

I am a graduate student pursuing my Master's degree in Biological Systems Engineering at the University of Nebraska-Lincoln. My research is using computational modeling to integrate the systems in the foodenergy-water (FEW) nexus. My current work involves connecting corn, water, ethanol, and beef systems to develop a comprehensive understanding of how these systems work together and affect each other. This will be a simplified model that will support the framework of an educational videogame that teaches the importance of systems-thinking in these fields.

\section{Dr. Jennifer Keshwani, University of Nebraska, Lincoln}

Jenny Keshwani is an Assistant Professor of Biological Systems Engineering and Science Literacy Specialist in the Institute of Agriculture and Natural Resources at the University of Nebraska-Lincoln. She is active in promoting science and engineering education in both formal and informal settings through her research, extension, and outreach activities. Dr. Keshwani is actively engaged in several cross-disciplinary regional and national efforts related to STEM education and outreach. Most recently, she was part of a team that received NSF funding to engage youth in STEM through wearable technologies.

\section{Dr. Jeyamkondan Subbiah P.E., University of Nebraska, Lincoln}

Jeyamkondan Subbiah is the Kenneth E. Morrison Distinguished Professor of food engineering at the University of Nebraska, Lincoln, with joint appointments in the Departments of Biological Systems Engineering and Food Science \& Technology. His research focuses on spectral imaging for predicting food quality (beef tenderness) and early diagnosis of human diseases (peripheral arterial disease). He has active research in the area of food safety engineering through integration of heat transfer model and predictive microbial growth/death models for food safety risk assessment. Every fall, he teaches a large sophomorelevel class on engineering properties of biological materials, which consists of both lectures and laboratory sessions with an enrollment of more than 70 students. Every spring, he teaches a junior-level course on principles of bioprocess engineering which has an enrollment of about 25 students.

\section{Dr. Ashu Guru, University of Nebraska, Lincoln}

Dr. Guru is a computer scientist and educational researcher who focuses on curriculum development in both formal and non-formal educational settings. His expertise includes systems thinking and design, operations research, statistical modeling, and simulation. He has taught several graduate and undergraduate courses in statistics, systems engineering, operations research, and business analytics. Dr. Guru has previously served as the Director of Research Strategy at the Jeffrey S. Raikes School of Computer Science and Management at the University of Nebraska - Lincoln. In addition to his academic experience, Dr. Guru is an expert in supercomputing; he has 10 years of experience in building and managing information technology solutions at University of Nebraska - Lincoln, Fermi National Lab, Talent Plus, and IBM.

\section{Nathan C. Rice, University of Nebraska, Lincoln}

I am a masters student at the University of Nebraska - Lincoln majoring in Biological Systems Engineering. My assistantship project focuses on developing an educational immersive simulation game to educate youth on the corn-water-energy-beef nexus and systems thinking. 


\title{
Educational immersive simulation game design to enhance understanding of the corn- water-ethanol-beef system nexus: Work In Progress
}

\begin{abstract}
Food, energy, and water are the three resources that are vital to nearly every process in the world. How people use these resources have long term effects on the world such as food security, water shortage, and greenhouse gas emissions. Learning how to quantify and use food, energy, and water efficiently is key to creating a sustainable life on Earth. The corn-water-ethanol-beef (CWEB) system is specifically significant to the economy of the Midwest United States. In this system, corn is grown on farms, which can feed beef cattle or be processed in an ethanol plant to create ethanol for energy. This paper will present the first phase of an interdisciplinary project to develop an educational immersive simulation game to enhance understanding of the complex interactions of the CWEB system nexus and its impact on global sustainability measures. The audience of this game will be middle school, high school, and undergraduate students. Users will play as either a corn farmer, beef rancher, feedlot manager, or an ethanol plant manager in this multiplayer game. Player decisions will impact overall system sustainability. Even though players are competing with each other, the overall goal is to be able to create a sustainable world in the year 2050. Users will learn not only the complexities of each agricultural system, but will also learn best management practices to increase sustainability. The game will be put together by developing simplified integrated models using existing research data and models describing corn, ethanol, and beef systems individually. The integrated models will also determine knowledge gaps in this system for future research. Validation will be done by coupling models with historical data to compare with past events such as droughts. Game theory will be implemented to design the social, economic, and environmental aspects of the model. Once a preliminary model is finished, it can be used to develop the simulation game framework. We expect this immersive simulation game will be a transformative educational tool to enhance systems thinking capabilities and increased understanding of the food, energy, and water nexus.
\end{abstract}

\section{Introduction}

The global population is predicted to reach 9 billion people and double food demand in the year 2050 (Godfray et al., 2011). This puts pressure on resources to be used wisely to support the world population. Today's youth and future generations will be most affected by the potential effects of a larger world population, including food shortages or climate change, and must be prepared and empowered to develop ways to create a more sustainable world. Food, energy, and water are highly interconnected systems. Understanding how each system affects the larger system is critical to making the best decisions economically and environmentally (Bazilian et al., 2011). Decisions made by stakeholders in one system invariably impact other systems. Abundant research exists on the understanding of individual systems and even connecting two of the 
mentioned systems. There is however very little research that ties together all three of the systems into a single Food-Energy-Water Nexus (FEW). Understanding this integrated system is key to making sustainable practices in the future. Therefore, there is a need to educate the upcoming generation on the FEW Nexus and the relevant processes that comprise it. Developing systems-thinking at a young age will influence world perspective and can improve problem solving skills (Bawden et al., 1984). It is not enough to simply teach students about each individual system but they must also understand the greater significance and impacts of each system on a larger scale.

The Corn-Water-Ethanol-Beef Nexus (CWEB) system is prominent in the Midwest United States and is an example of an application of the FEW Nexus. Corn is the largest crop grown by farmers in the Midwest according to USDA (2016). In addition to food production, corn grain is used for ethanol production, feeding livestock, and the distillers grains from the ethanol plants are high value feed for the beef cattle industry. The FEW Nexus is briefly illustrated in Figure 1. The system as a whole interacts with the environment through the use of water, energy, and emission associated with the various processes in the system. Teaching students how these systems work and how they are connected will greatly influence upcoming generations of agricultural producers and consumers. Being mindful of the larger system will encourage sustainable practices that are more aware of the environmental impacts of their decisions.

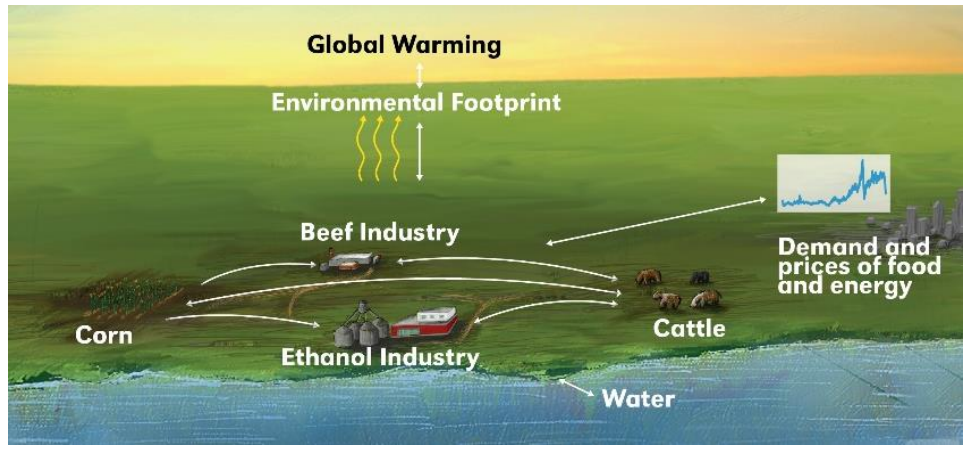

Figure 1: Interactions of the CWEB nexus

The goal of this multi-year NSF funded-project is to create an educational immersive simulation videogame that will teach students the importance of the CWEB Nexus and foster systemsthinking skills. In this game, users can play as corn farmers, cattle ranchers, feedlot managers, or a combination of the mentioned professions with ethanol and water systems. Students will not only be taught how these systems work but how they are related to each other and how any decision they make will have larger impacts. This videogame will act as an engaging, interactive way of teaching that will promote systems-thinking by the users. There are three components in this project: building the framework for an educational immersive simulation game, preparing FEW and systems thinking curriculum for education and outreach, and developing a simplified corn-water-ethanol-beef (CWEB) model that will be drive the mechanics of the game. Most of 
the current progress presented in this Work-In-Progress paper is focused is in the development of the CWEB model but future planning for the other two goals has taken place as well.

\section{Building an educational immersive simulation game}

Research overwhelmingly indicates serious games and interactive multimedia learning tools can help users understand concepts better than traditional education practices and are powerful tools to achieve positive behavioral change (Dede, 2009). A framework and game flow for the educational videogame must be identified before the actual game development. A list of educational objectives that must be met will be outlined in an educational curriculum. Educational objectives of the game will include technological advancements in technology, the impacts of sustainability, and the diminishing availability of resources for farmers. A clear game flow will define how the model will be built and how the user will interact with the game. Stepby-step instructions will include wireframes and verbal descriptions to assist the graphics team in the development of screens and the programming team in connecting system components.

Many considerations in the game flow are still in progress. The game can either be turn-based or real-time which define whether the underlying model will be discrete or continuous. The game can also be simulated either daily, seasonally, or annually which will affect the time period of the model simulations. Other game flow aspects will also be considered which will affect the user interface and how screens will appear. After identifying design specifications, a design studio team will undertake the engineering, development, and deployment of the CWEB system educational game. The team will consist of 4-6 undergraduate computer science students as their capstone design project during the 2017-2018 academic year.

\section{Educational Objectives and Goals}

The long-term objective of this project is to educate students on the importance of thinking across FEW related areas in a growing world. The game will be distributed to 4-H programs across the state that can be incorporated into interactive camps. High school teachers will incorporate the game as an interactive tool to teach agricultural systems and cross-systems thinking. Finally, "FEW in Society" is a new university minor catered towards students from various disciplines interested in FEW issues. These students will be exposed to the educational CWEB game as an experiential learning opportunity. Instructors in the minor courses will utilize the game to foster systems-thinking skills. To cater to the diverse audience of this game, there will be three versions that will eventually be released. The complexity of the game will match the age based on whether the user/class is in middle school, high school, or university-level. Currently, our plan is to design the base complexity for the high school age student with modifications built in to enhance complexity for university level students (through embedded gaming campaigns that can be unlocked) or simplifications for middle school students through 
options for preset decisions. As part of the project, we also have budgeted for science curriculum writers that will developing lesson pans and supporting resources to teach implications of decisions relative to alternative inputs of water and energy to the CWEB systems. Another unique aspect related to this the experiential learning opportunities for four and ten undergraduate students, during second and third year. Students will be partnered with extension personnel on this project and will work with them to engage with youth and adults at various non-formal venues to deliver educational programs utilizing the CWEB educational game. Nebraska Extension has established relationships with producer groups, commodity boards, afterschool programs, 4-H clubs, and museums that will provide ample experiential learning opportunities. The undergraduate students will travel to the campsites and demonstrate the game by engaging $4-\mathrm{H}$ members in gaming sessions.

There are three major learning objectives for the game:

\section{Agricultural Appeal and Literacy}

Recent global trends show that larger percentages of the rural and farming population are moving to urban areas (United Nations, 2014). Powell and Agnew (2011) argue that even in agricultural states, the majority of Americans have no direct links to agriculture as they are two to four generations removed from the farm. As a result, the public lacks the knowledge and appreciation of the food, fuel, and fiber it demands. The importance of agricultural literacy is also addressed through this project. There is a growing disconnect between the American public and the people who make their food. Organizations like the American Farm Bureau Foundation for Agriculture are working to rebuild trust between those who live in urban and rural areas by educating more people in agriculture (American Farm Bureau Foundation for Agriculture, 2017). Users who play this videogame will have a better understanding of the lifestyle that farmers live and the work that must be done to grow food. The National Agricultural Literacy Outcomes (NALOs) are being used to guide the incorporation of agricultural and natural resource information. The NALOs were developed (Speilmaker \& Leising, 2013) to define the knowledge and skills that should be achieved at specific grade levels to ensure an agriculturally literate society. In addition to increasing agricultural awareness, this game will emphasize modern agriculture and the technology involved to attract students to pursue careers related to agriculture.

\section{Systems Thinking}

As stated before, students playing this game will be able to think across systems and understand how their decisions impact other systems. If a user decides to grow a certain crop in a given season, it will affect the market and other systems that rely on that crop. That decision may also have implications that affect the environment and climate change. Users should be able to assess the impacts of their decisions and how they affect not only themselves but others too. It is also a 
step towards combining several different disciplines into one curriculum. Classes are normally taught in a compartmentalized way where history, math, literature, etc. are all taught completely separate from each other. However, most disciplines and issues in the real world involve application of many different traditional subjects and students are not taught how to approach this at a young age. Students who are able to understand how everything they learn is interconnected in some way will become more successful in the future and be more prepared to solve the world's problems (Sweeney, 2017). In this game, users will be able to directly connect several different systems and disciplines very quickly. The game will not only educate how corn, water, ethanol, and beef systems are connected, but will also show how solving problems requires thinking across many different subjects such as science, agriculture, economics, and statistics. Curricula to accompany the game will be developed to foster essential competencies needed for systems-thinking such as causal loops diagrams and behavior-over-time graphs to visualize the interdependencies and patterns in the system (Kim, 1999).

\section{Long-term Sustainability}

The game will simulate the FEW Nexus through the year 2050 and show impacts of user decisions on world sustainability and food growth. The user will be able to assess how sustainable their practices are because they will be assigned a sustainability score based on the decisions they make. Therefore, they will be able to see how they are helping or hurting the world and if these practices can be sustained in the long term. Users would be predominantly interested in making profits in the short term, but if they are not aware of their effect on the environment, it may adversely affect them in the future. The game must make users mindful of both economic and sustainable consequences of their actions.

\section{Development of the Integrated Model}

With the project in its early stages of development, creating the integrated model is the first step. This process involves identifying existing models and data that are relevant to their respective systems and connecting them where appropriate. Many researchers have investigated the effect of climate change on the hydrological condition of the land (Taylor, et al., 2013; Bridode, et al., 2013), the effect of water management on crop productivity (Mueller, et al, 2012; Knox, et al., 2012), the water and energy use information in ethanol plants (Wang et al., 2012) and beef plants (Ziara et al., 2016; Ran et al., 2016), and the agricultural economics aspects of each of these activities. These models have been developed separately to understand partial relationships in the system. However, the change in one component of the coupled FEW nexus impacts all other components closely and perhaps simultaneously. Thus, a multi-disciplinary approach is needed for better understanding how these various components of the nexus are coupled, their interactive cause-effect relationships, and their "individual" as well as "collective sustainability" attributes over time. The following work shows models that have been chosen for integration and data that 
still needs to be added. The flow chart for connecting the models and their inputs/outputs is shown in Figure 2.

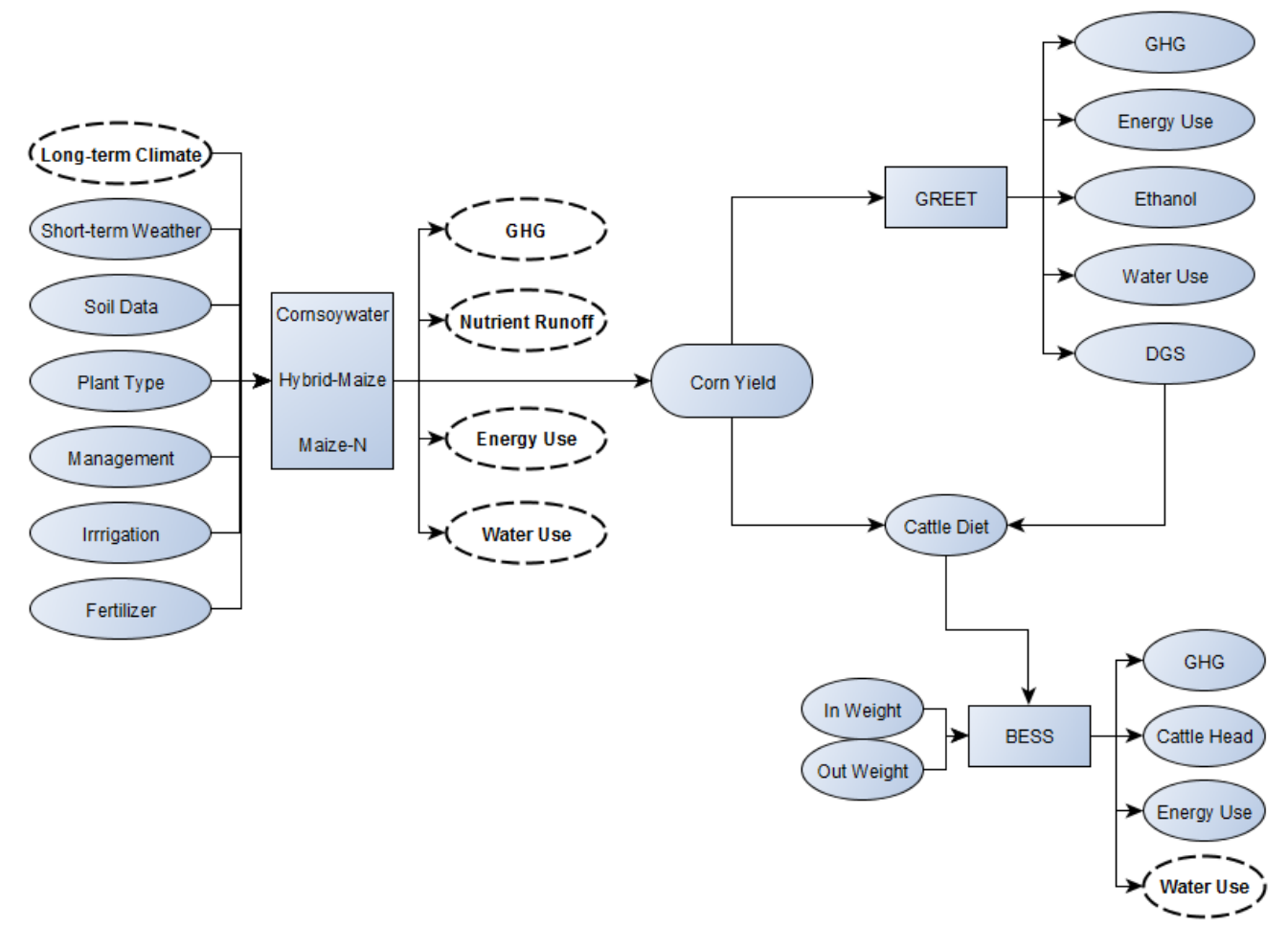

Figure 2: Model flow chart. Existing inputs/outputs are shaded while components to be added are white and have dashed lines

\section{Current models being integrated}

There are three models that were chosen because they are accessible and well-accepted for their respective fields: Hybrid-Maize for corn cropping; Greenhouse gases, Regulated Emissions, and Energy use in Transportation Model (GREET) for ethanol production; and Biofuel Energy Systems Simulator (BESS) for feedlot beef production. Hybrid Maize was developed to be used as a decision support system for corn farmers. The farmer can enter the necessary inputs as shown in Figure 2 into the model, and Hybrid Maize would simulate the corn yield possible under these parameters. Weather data is based on the location of the weather station of interest and gives information on rainfall, maximum temperature, minimum temperature, solar radiation, relative humidity, and day of the year. There are several datasets that can provide this data including the High Plains Regional Climate Center (HPRCC) and the National Oceanic and Atmospheric Administration. The user can enter soil data which includes rooting depth, soil texture, soil moisture, and bulk density. These are all inputs that are based on the location of the user's farm and are relevant inputs to simulate corn yield. It also lets the user decide how long to 
grow before harvest, how much irrigation to use, and the cultivar being planted (Yang et al., 2016). Examples of outputs from this model are shown in Figures 3 and 4.

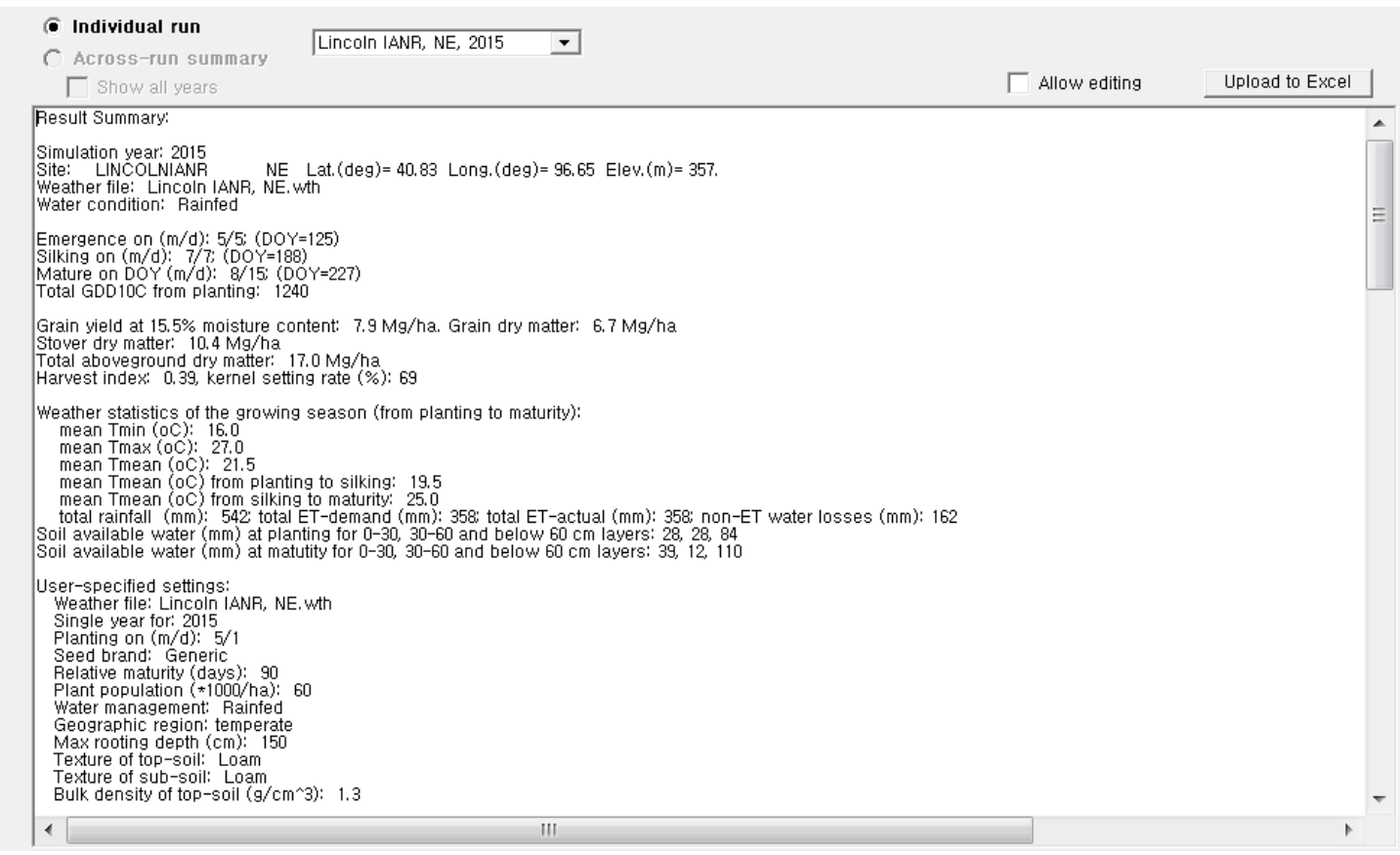

Figure 3: Summary of Hybrid-Maize outputs for a given scenario and year

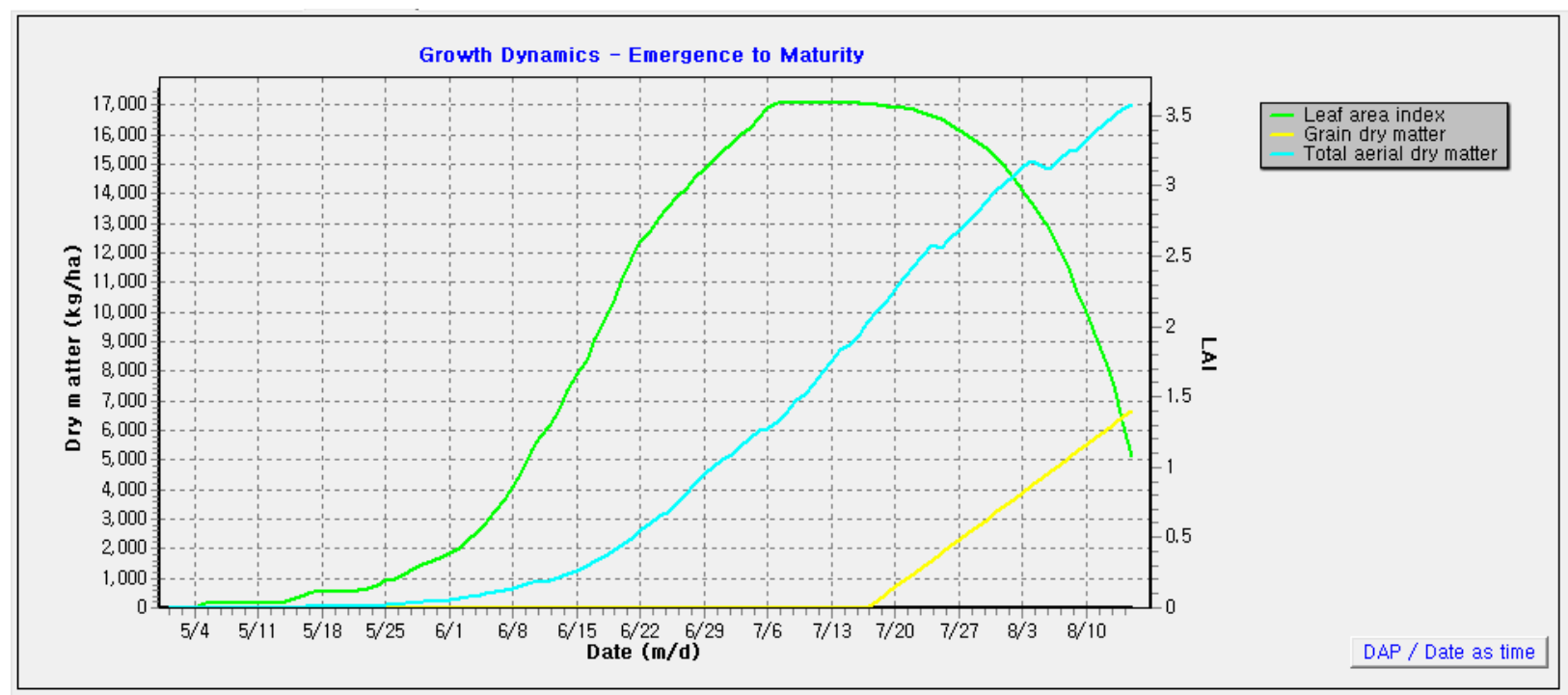

Figure 4: Growth of crop throughout growing season in Hybrid-Maize

Closely associated models Maize-N and Cornsoywater were created by the same developers and take the same inputs to determine optimal fertilizer and irrigation use for the given scenario respectively. While these programs calculate fertilizer and irrigation as outputs, we would like to use these parameters as inputs that will simulate corn yield by manipulating the models. 
The GREET model is a life cycle assessment model of various fuel resources, including corn ethanol. It is created by Argonne National Laboratory and tracks the environmental impacts of processing fuel types from cradle to grave. For GREET, the lone input is corn yield which is provided by the cropping model. This is how GREET will be connected to Hybrid Maize. It will calculate ethanol yield as well as environmental requirements to produce it such as water use, energy use, and greenhouse gas emissions. It will also calculate how much distillers grains is produced as a byproduct which is an important part of the beef system as well (Wang et al., 2014). While the ethanol system is not controlled by a user, it can be simulated by a computer as it is still a vital component of the CWEB nexus. BESS is a similar model but also includes production of beef in the feedlot system. One of its inputs (Figure 5) includes cattle diet which is composed of corn yield from Hybrid-Maize and DGS from GREET. It is through these values that the BESS model is connected to the two other models. The user can also input the "in weight" of the calf and the desired "out weight" at which the cow is finished and sold. The player can control all of these inputs in the game which will give beef to be sold (Liska et al., 2009).

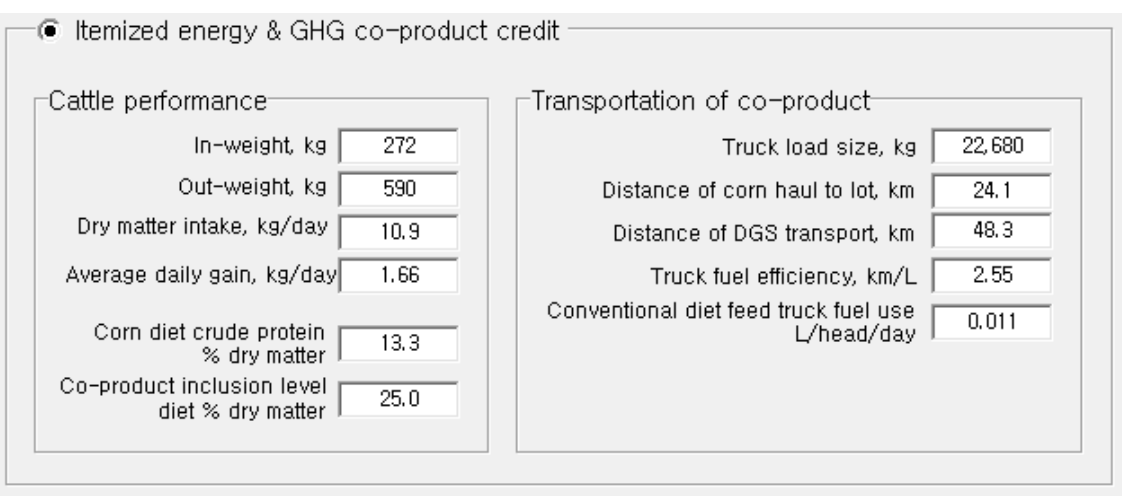

Compute

Figure 5: BESS inputs for cattle feedlot system

\section{Additional models needed}

There are still several models that need to be added that are both randomly simulated in the environment and affected by user actions. In the existing models, Hybrid-Maize doesn't calculate the environmental effects of cropping such as energy use, greenhouse gas emissions, and runoff which need to be included to determine sustainability. Users will need to decide on certain management practices as well such as tilling, pesticides, fungicides, and manure. The BESS model also doesn't calculate the amount of water needed to grow beef so that also needs to be incorporated. The entire cow/calf system before the feedlot is also missing so a model that simulates that must be found. 
Being able to generate short term weather and long term climate is very important to this system. Historical weather data needs to be retrieved by location to randomly generate weather inputs such as rainfall and temperature on a day-to-day basis. The data generated directly affects corn growth but can also contribute to environmental issues. Users will have to understand and manage droughts, floods, nutrient runoff, and natural disasters that are a part of these weather models. Water availability is important for farmers to be able to track and will influence many decisions as well. While these short term weather models will directly affect farmers, the game should be able to model long term climate data to simulate climate change. Users should be able to understand the effect that their actions have on climate change if their practices are not sustainable. If players continuously make decisions that increase their profits but are not environmentally friendly, it will affect their sustainability score and increase the amount of greenhouse gas in the atmosphere. We will incorporate a model that will increase the randomness of weather in future years which will create more storms and more extreme weather conditions. Thus, it would be in the best interest of players to be mindful of the environment and their sustainability score. It will encourage users to not only think across systems but to also be aware of how their decisions impact the future. The team will either need to find existing models of long term climate change or use experts to develop a reasonable way to model this.

Since the goal is to feed the world in 2050, population growth models will show users their progress towards reaching this goal. These growth models will incorporate real projections leading up to 2050 as well as total food storage produced in the game. If a player prioritizes profit over yield, the game should be able to determine how well the global food storage will feed the global population. Finally, interactions between users and other farmers will be linked via the purchasing of goods. Farmers, either player-controlled or computer-simulated, will be able to buy and sell commodities from and to each other and prices will be determined by the market. The world market will be simulated based on existing data and economic models. Game theory will be incorporated to represent the significance of trade-offs for the user.

Connection of all of the models will be done using an Application Program Interface (API). The API will act as a server that will call each of the models and run them according to certain routines and actions built into the program. Figure 6 displays how the API will work and run the system for the game. Inputs will be fed into their respective models and the models will run and interact with each other based on commands set by the API. The API will run in the background of the game and send outputs to the game interface. The game will translate the outputs so that it is playable and easily understood by the user. 


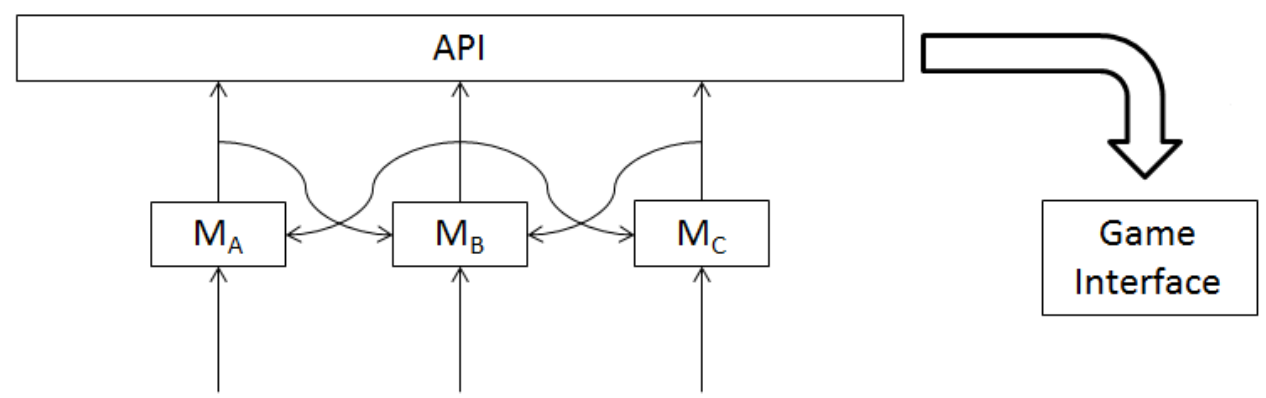

Figure 6: Schematic of API framework that will be used to connect the models and the game interface

\section{Conclusion}

Using integrative computer modeling is an innovative and engaging approach to educating students on systems-thinking. This educational simulation videogame will serve as an immersive way to not only teach about agricultural systems, but will develop systems-thinking skills. The game will encourage students to think more wisely about using resources and understand the implications of a single decision on larger systems. Current work in this multi-year project presented in this paper has focused on identifying and integrating research-based models to provide the data needed to guide game flow and scenarios in the videogame. 


\section{References}

1. American Farm Bureau Foundation for Agriculture. 2017. What We Do. American Farm Bureau Federation.

2. Bawden, R.J., Macadam, R.D., Pakham, R.J. and Valentine, I. 1984. Systems thinking and practices in the education of agriculturalists. Agricultural Systems. 13(4): 205-225.

3. Bazilian, M., Rogner, H., Howells, M., Hermann, S., Arent, D., Gielen, D., Steduto, P., Mueller, A., Komor, P., Tol, R. and Yumkella, K.K. 2011. Considering the energy, water, and food nexus: Towards an integrated modelling approach. Energy Policy. 39: 7896-7906.

4. Brigode, P., Oudin, L. and Perrin, C., 2013. Hydrological model parameter instability: A source of additional uncertainty in estimating the hydrological impacts of climate change? Journal of Hydrology, 476, pp.410-425

5. Dede, C. 2009. Immersive interfaces for engagement and learning. Science, 323(5910): 66.

6. Godfray, H.C.J., Beddington, J.R., Crute, I.R., Haddad, L., Lawrence, D., Muir, J.F., Pretty, J., Robinson, S., Thomas, S.M. and Toulmin, C. 2010. Food Security: The Challenge of Feeding 9 Billion People. Science. 327: 812818.

7. Kim, D. 1999. Introduction to Systems Thinking. Pegasus Communications. Retrieved from TheSystemsThinker.com

8. Knox, J.W., Kay, M.G. and Weatherhead, E.K., 2012. Water regulation, crop production, and agricultural water management - understanding farmer perspectives on irrigation efficiency. Agricultural Water Management, 108, pp.3-8.

9. Liska, Adam; Yang, Haishun; Walters, Daniel T.; Cassman, Kenneth; Klopfenstein, Terry; Erickson, Galen; Bremer, Virgil R.; Koelsch, Richard K.; Kenney, Dan; and Tracy, Patrick, "BESS: Biofuel Energy Systems Simulator: Life Cycle Energy \& Emissions Analysis Model for Corn-Ethanol Biofuel Production Systems -- User's Guide for the BESS model" (2009). Adam Liska Papers. Paper 4

10. Mueller, N.D., Gerber, J.S., Johnston, M., Ray, D.K., Ramankutty, N. and Foley, J.A., 2012. Closing yield gaps through nutrient and water management. Nature, 490(7419), pp.254-257.

11. Powell, D. V., \& Agnew, D. M. (2011). Assessing agricultural literacy elements of project food land and people in K-5 using the food and fiber systems literacy standards. Journal of Agricultural Education, 52(1), 155-170. doi: $10.5032 /$ jae. 2011.01155

12. Ran, Y., Lannerstad, M., Herrero, M., Van Middelaar, C.E. and De Boer, I.J.M., 2016. Assessing water resource use in livestock production: A review of methods. Livestock Science, 187, pp.68-79

13. Spielmaker, D. M., \& Leising, J. G. (2013). National agricultural literacy outcomes. Logan, UT: Utah State University, School of Applied Sciences \& Technology. Retrieved from http://agclassroom.org/teacher/matrix

14. Sweeney, L.B. 2017. Learning About Systems. Lindaboothsweeney.net

15. Taylor, R.G., Scanlon, B., Döll, P., Rodell, M., Van Beek, R., Wada, Y., Longuevergne, L., Leblanc, M., Famiglietti, J.S., Edmunds, M. and Konikow, L., 2013. Ground water and climate change. Nature Climate 
Change, 3(4), pp.322-329

16. United Nations (2014) World Urbanization Prospects: The 2014 Revision, Highlights (ST/ESA/SER.A/352). United Nations, Department of Economic and Social Affairs, Population Division.

17. Wang, M., Han, J., Dunn, J.B., Cai, H. and Elgowainy, A., 2012. Well-to-wheels energy use and greenhouse gas emissions of ethanol from corn, sugarcane and cellulosic biomass for US use. Environmental Research Letters, 7(4), p.045905.

18. Wang, Z., Dunn, J.B. and Wang, M.Q. 2014. Updates to the Corn Ethanol Pathway and Development of an Integrated Corn and Corn Stover Ethanol Pathway in the GREET Model. Argonne National Laboratory.

19. Yang, H.S., Dobermann, A., Cassman, K.G., Walters, D.T. and Grassini, P. 2016. Hybrid-Maize: A Simulation Model for Corn Growth and Yield. University of Nebraska-Lincoln.

20. Ziara, R., Li S., Dvorak, B., Subbiah, J., 2016. Water and energy use of antimicrobial interventions in a mid-size beef packing plant. American Society of Agricultural and Biological Engineers Applied Engineering in Agriculture, 32(6), 873-879. 